DOI: https://doi.org/10.15688/lc.jvolsu.2018.2.13

UDC $34(37)+342.5$

LBC 67.3

\title{
THE PREDECESSORS OF THE MAGISTRACY OF PRAETOR IN ANCIENT ROME
}

\author{
Olga A. Vlasova \\ Yaroslavl Branch of Moscow Finance and Law Academy, Yaroslavl, Russian Federation
}

Introduction: the praeture played a very important role not only in the formation of Roman law, but also contributed to the stabilization and improvement of the public administration of the Republic of Rome, in this connection, the actual purpose of the study is to identify the predecessors of the magistracy of praetor, on whose experience the Romans relied in the creation of a new position. Methods: the general scientific methods of research, such as analysis, synthesis, comparison, as well as the special historical and special legal methods are used. Results: in the course of the work there were analyzed the posts of military tribunes with the consular power, of the prefect of the city, the chief of cavalry and the College of pontiffs. Conclusions: the study has revealed the role of the predecessors of the magistracy of praetor, defined the specificity and scope of their activities, which influenced the creation and formation of the praeture.

Key words: local administration, public Roman law, Roman Republic, consular tribune, prefect of the city, pontiffs, head of a cavalry.

УДК 34(37)+342.5

ББК 67.3

\section{ПРЕДШЕСТВЕННИКИ МАГИСТРАТУРЫ ПРЕТОРА В ДРЕВНЕМ РИМЕ}

\author{
Ольга Александровна Власова
}

Ярославский филиал Московской финансово-юридической академии, г. Ярославль, Российская Федерация

Введение: претура сыграла очень важную роль не только в формировании римского права, но и способствовала стабилизации и повышению эффективности государственного управления республиканского Рима, в связи с чем актуальной является цель исследования - выявить предшественников магистратуры претора, на опыт которых римляне опирались при создании новой должности. Методы: использованы общенаучные методы исследования, такие как анализ, синтез, сравнение, а также специально-исторические и специально-юридические методы. Результаты: в ходе работы были проанализированы должности военных трибунов с консульской властью, префекта города, начальника конницы и коллегия понтификов. Выводы: в результате исследования выявлена роль предшественников магистратуры претора, определены специфика и сферы их деятельности, которые повлияли на создание и формирование претуры.

Ключевые слова: претура, римское публичное право, Римская республика, консулярные трибуны, префект города, понтифики, начальник конницы.

\section{Введение}

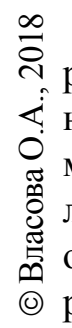
имского публичного права являются неотьемлемой частью научного наследия многогранной античной цивилизации, составляющей основу современного европейского общества. Одним из важнейших элементов римской civitas была магистратура претора, созданная по закону Лициния - Секстия в 367 г. до н. э. Именно благодаря функционированию претуры в римском частном праве появилась важная специфическая часть - преторское право, ius honores. Сама деятельность преторов оказала существенное влияние на развитие римской государственной системы эпохи Республики. Тем не менее претура редко становилась предметом исследовательского 
интереса правоведов и историков, и многие аспекты ее создания, эволюции и функционирования требуют более углубленного изучения. Одним из таких аспектов является вопрос о предшественниках претуры, тех государственных структурах, используя опыт которых магистратура претора могла функционировать настолько эффективно.

Изучение римской государственности возможно только в рамках междисциплинарного подхода, поскольку предполагает использование и специальных исторических методов, и специально-юридических методов, учитывающих специфику государственных и правовых явлений.

\section{Консулярные трибуны (tribuni militum consulari potestate)}

Военные трибуны с консульской властью впервые избираются в Риме в 444 г. до н. э. согласно принятому в центуриатных комициях закону от 445 г. до н. э. (lex de tribunis militum consulari potestate creandis). Характерным для магистратуры было представительство в ней и плебеев, и патрициев; наличие у консулярных трибунов высшей власти, империя (Liv. IV. 7. 2; Gell. XVII. 21. 19); многочисленность и нестабильность состава магистратуры: от трех до девяти трибунов.

Создание новой должности было вызвано целым комплексом причин, из которых мы выделим две. Первой причиной создания консулярного трибуната явилось то обстоятельство, что консулы явно не справлялись с текущими проблемами, не успевая адекватно и воевать за пределами Рима, и решать проблемы, возникавшие в самом городе. Второй причиной послужила сословная борьба между патрициями и плебеями, о чем недвусмысленно сообщает Ливий (Liv. IV. 6. 1-11). Следует отметить, что он говорит о патрициях, решившихся на создание новой магистратуры как на компромисс - это та же самая причина, которая стояла, по мнению Ливия, и за созданием претуры в 367 г. до н. э. Эту же причину в качестве основной приводит и Дионисий Галикарнасский (Dionys. XI. 56-61).

Деятельность военных трибунов с консульской властью была разнообразна и сравнима по масштабу и объему с деятельностью консулов (не следует забывать, что магистратуру консулов никто не отменял и годы консулярного трибуната сменялись годами ординарного консулата). Основные обязанности tribuni militum consulari potestate заключались в поддержании стабильного существования римской общины и, конечно, ведении военных действий.

В.В. Дементьевой был дан развернутый анализ военных действий, проводимых консулярными трибунами. Военные трибуны с консульской властью редко одерживали победы, в основном незначительные, и слишком часто терпели поражения, в том числе весьма внушительные. Автор отмечает, что неэффективность и опасность множественного империя при ведении военных действий вынуждала римлян не раз заменять консулярных трибунов диктатором, и делает вывод, что применение магистратуры tribuni militum consulari potestate в условиях военного времени в целом, по всей видимости, себя не оправдало [7, с. 169-172].

Не всегда успешную деятельность консулярных трибунов подчеркивает К. Бреннан, говоря, что существование «троих или более главных магистратов с равной властью не представляется хорошей идеей», особенно в первой половине IV в. до н. э. [14, p. 58-59].

Действительно, практически вся первая половина IV в. до н. э. отмечена военными неудачами Рима. В 390 г. до н. э. произошло галльское нашествие, результатом которого стал захват Рима, лишь на Капитолии укрылась небольшая часть римского войска (Liv. V. 35-49. 7). Покинутый большинством жителей город был разграблен и сожжен. Осада Капитолия длилась семь месяцев. Нашествие завершилось выплатой очень крупной суммы контрибуции. Насколько тяжелы были последствия войны, можно судить хотя бы по тому, что с тех пор день разгрома римского войска на берегах реки Аллии 18 июля 390 г. до н. э. - был в Риме днем народного траура (dies Alliensis). Угроза со стороны галлов сохранялась в течение всего столетия, лишь в конце 30-х гг. IV в. до н. э. римляне заключили с галлами мир. Воспользовавшись сложной ситуацией, союзники Рима также начали борьбу с Городом.

Не более успешными были действия консулярных трибунов в самом Риме. Они с тру- 
дом смягчали противоречия между патрициями и плебеями; постоянно подвергались нападкам плебейских трибунов по самым разным, но неизменно важным для римского народа поводам (Liv. IV. 25. 9-14; IV. 48. 1-4; V. 2. 9-10; V. 9. 4; V. 10-11; V. 16. 5; VI. 35.10 и т. д.); не могли избежать и конфронтации внутри магистратуры (события 424 г. до н. э.). В любом случае наличие большого числа высших должностных лиц, обладающих империем и ius intercessionis (правом наложить запрет на решения коллеги), не могло фактически способствовать стабильности в условиях той сложной внутри- и внешнеполитической обстановки, которая сложилась в Римской республике во второй половине $\mathrm{V}$ - начале IV в. до н. э.

Тем не менее хотя коллегия военных трибунов с консульской властью показала себя не слишком эффективной, она дала возможность римлянам осознать, что государству требуется более чем два должностных лица cum imperio, но при этом необходимо наличие консульского контроля и обязательной иерархичности власти.

\section{Префект города (praefectus urbi)}

Должность префекта города по сути своей - одна из самых древних должностей Рима. Согласно общепринятым данным ее создал еще Ромул и в то время она носила несколько иное название - custos urbis. Этот чиновник действовал от имени царя и в его отсутствие управлял Римом. С 450 г. до н. э. название должности было изменено на praefectus urbi. Префекта назначал по собственному выбору тот высший магистрат, который последним покидал город - очевидно, чтобы обеспечить наличие в Риме законной власти. Дискуссионными остаются вопросы, являлся ли префект магистратом, избирался ли он на куриатных комициях или нет, а также обладал ли префект города империем $[6$, с. $72 ; 10$, с. 76-85; 14 , p. 35-37; 17, s. 110-112]. Мы можем с достаточной степенью уверенности утверждать, что префект должен был обеспечить безопасность Рима, а следовательно, имел право командовать войсками, вершить суд и в целом осуществлять iurisdictio, решать админист- ративные задачи (Tac. Ann. 6. 11. 1; D. 1. 2.2. 33; Dionys. VI. 2. 3; 42. 1; 8. 64. 3; 9. 69. 2; Liv. III. 5. 3; 8. 7; 9. 6; 29. 4; Gell. XIV. 7. 4).

Еще Бартольд Нибур высказал мнение, что к претору переходили обязанности префекта города после появления новой магистратуры [16, p. 363]. И действительно, в отсутствие консулов именно претор оставался высшим магистратом в Риме, на его плечи ложилась забота о безопасности Рима и стабильном функционировании всей государственной системы. Именно претор начальствовал и ведал Римом, как не раз говорил об этом Ливий (Liv. X. 22. 7-8; XXIV. 9. 5). В обязанности преторов входили: custodia urbis (непосредственная защита Рима и обеспечение его обороноспособности) [2, с. 31-33]; административная сфера, в том числе созыв сената (Liv. XLII. 21. 8; XXXII. 26. 4-18; XXXVIII. 44. 9; Cic. De leg. III. 10; Gell. Noct. Att. XIV. 7. 4); дипломатические обязанности [3, с. 12-16]; сакральная деятельность [4, с. 43-49].

С 367 г. до н. э., когда появляется претуpa, praefectus urbi назначается лишь на очень краткое время латинских празднеств в честь Юпитера Латиария, когда консулы были обязаны покинуть стены Рима и присутствовать на Альбанской горе. Возрождается должность префекта города только при Октавиане Августе, однако уже на совершенно других основаниях и с четко определенными - и весьма существенными по объему - полномочиями.

\section{Коллегия понтификов (collegium pontificum)}

Согласно античной традиции коллегия понтификов появляется при царе Нуме и практически с самого своего основания обладает весьма широкими полномочиями (Liv. I. 20. 6; Dionys. II. 73. 1-2; Plut. Numa. 9; Lyd. mag. I. 35; Fest. P. 113L, 200L). Античные авторы настолько высоко оценивали значение коллегии понтификов, что Т. Моммзен даже посчитал возможным признать наличие у верховного понтифика магистратских полномочий, империя и ауспиций $[15$, s. $18-73]$. Эта концепция породила в историографии целое направление, которое, впрочем, подвергается некоторой критике в современной исследовательской литературе [13, с. 265-266, 529-530]. 


\section{ТЕОРИЯ И ПРАКТИКА ГОСУДАРСТВЕННО-ПРАВОВОГО РАЗВИТИЯ}

Для нас существенное значение имеет цитата из Дигест, в которой Помпоний (D. 1. 2. 2. 6), сообщая об учреждении законов XII таблиц, напрямую пишет, что знание права, толкование законов и иски на их основе были в руках коллегии понтификов, и «каждый год устанавливали, кто из коллегии будет начальствовать над частными делами. И народ придерживался этого обычая почти сто лет» [8]. Законы ХІІ таблиц были созданы в 451-450 гг. до н. э., а почти через сто лет, в 367 г. до н. э., появляется магистратура претора. Таким образом, Помпоний явно полагает, что с появлением новой магистратуры судебные обязанности по частным делам (praeesse privatis) перешли из рук понтификов в руки претора.

Одним из первых в отечественной науке эта гипотеза - основанная на утверждениях Помпония и Лида (Lyd. mag. I. 35) - была предложена известным русским правоведом С.А. Муромцевым еще в 80-х гг. XIX в. [12, с. 167]. Ряд современных исследователей поддерживает eе, полагая, что понтифики не только консультировали римлян по поводу понимания права, но и руководили судебным процессом на его первой стадии [1, с. 67-90]. Наиболее полно эта точка зрения нашла отражение в работах Л.Л. Кофанова, уточнившего ряд положений [9, с. 10-12]. По мнению Л.Л. Кофанова, до законов Лициния - Секстия существовало разделение обязанностей: консулярные трибуны обладали юрисдикцией в сфеpe iudicia pubblica, за понтификами была закреплена iudicia privata. После же создания претуры понтифики, оставаясь авторитетными специалистами в области права, помогали претору, который обращался к ним за советом.

Однако вопрос о судебных полномочиях понтификов в сфере частного права остается дискуссионным. С точки зрения А.М. Сморчкова, посвятившего ряд работ анализу роли и места коллегии понтификов в системе государственности Древнего Рима, несмотря на то что источники позволяют предположить, что в ранний период понтифики могли обладать судебными функциями, разрабатывать иски и заниматься юридической теорией, этот вопрос остается открытым, поскольку конкретные примеры судебной деятельной этой жреческой коллегии отсутствуют [13, c. 281-282].
С нашей точки зрения, анализ источников и научных теорий, существующих в исследовательской литературе, все же позволяет считать понтификов предшественниками преторов в области судопроизводства.

\section{Начальник конницы (magister equitum)}

Предшественником претуры также могла являться экстраординарная должность magister equitum. Крайне интересную информацию содержит фрагмент речи Цицерона, где сравнивается положение претора с положением начальника конницы (De leg. III. 9): «Да будет при нем (диктаторе) начальник конницы, равноправный со всяким, кто будет ведать правосудием» [11].

Magister equitum являлся неизменным спутником и заместителем диктатора (magister populi), об этом свидетельствую многочисленные источники, в том числе и фасты. Кандидатуру начальника конницы определял диктатор при своем назначении; если начальник конницы погибал, то его должность как можно скорее замещалась (suffect) (Liv. IX. 22. 6); даже если диктатор призывался для невоенных целей - вроде ритуала вбития гвоздя или проведения игр (диктаторы imminuto iure) - наличие magister equitum оставалось обязательным (Dionys. V. 72. 2).

Дискуссионным является вопрос об обладании начальником конницы империя. К. Бреннан признает за начальником конницы только наличие ауспиций, а вопрос об обладании им империя предпочитает оставить открытым [14, p. 43-47]. В.В. Дементьева и Н.Н. Трухина, в свою очередь, полагают, что magister equitum был наделен империем [5, c. 110-111].

Позиции претора и начальника конницы многое сближало. Так же как и претор в отношении консулов, magister equitum был подчинен и подконтролен диктатору. Обязательность распоряжений диктатора для начальника конницы подчеркивали Полибий (III. 87. 9) и Ливий (VI. 39. 4). Как и консул, диктатор не мог лишить начальника конницы его должности, даже если был недоволен его действиями (мог лишь отстранить его от обязанностей) (Liv. VIII. 36). Однако необходимо учитывать, что сход- 
ство пары консул - претор и пары диктатор начальник конницы носит в большей степени внешний характер, а в их отношениях много существенных различий [5, с. 111].

Гораздо более важным, чем внешнее сходство, для нас является то обстоятельство, что система взаимоотношений, которые были выстроены в паре диктатор - начальник конницы, позволила римлянам на практике опробовать подобное вертикальное соотношение власти, когда империй одного магистрата оказывается большим или меньшим, чем у другого магистрата, не по объему полномочий, а по иерархии должностных лиц. Именно эта система в дальнейшем и была применена при создании ординарной магистратуры претора.

\section{Выводы}

Таким образом, конституированию претуры в государственно-правовой системе Рима способствовало наличие ее предшественников. При создании магистратуры претора был учтен опыт tribuni militum consulari potestate, особенно в вопросах ведения военных действий, когда наличие нескольких должностных лиц с высшей властью и правом управлять войсками способствовало военным победам римского государства. Также римляне опирались на опыт префекта города в области административного управления и обеспечения безопасности Рима. Коллегия понтификов передала претору право судопроизводства, оставшись в дальнейшем в роли советников по вопросам права. Структура должностных взаимосвязей диктатора и начальника конницы дала римскому обществу необходимый опыт выстраивания властной иерархии для магистратов с империем, что отразилось в структуре отношений претора с консулами. В целом можно утверждать, что появление претуры было вызвано тем многообразным опытом, который успела накопить и апробировать государственно-правовая система республиканского Рима к середине IV в. до н. э.

\section{СПИСОК ЛИТЕРАТУРЫ}

1. Боровков, П. С. Коллегия понтификов в политико-правовой структуре римской civitas (от цар- ского периода до конца Классической республики) : дис. ... канд. ист. наук / Боровков Павел Сергеевич. Екатеринбург, 2009. - 231 с.

2. Власова, О. А. Деятельность римского претора: custodia urbis / O. А. Власова // Город в Античности и Средневековье: общеевропейский контекст : докл. Междунар. науч. конф., посвящ. 100-летию г. Ярославля / отв. ред. В. В. Дементьева. - Ярославль, 2010. - Ч. ІІ. - С. 31-33.

3. Власова, О. А. Дипломатические обязанности претора в Риме / О. А. Власова // Ярославский хронограф : докл. науч. конф., посвящ. 20-летию ист. фак. ЯрГУ / отв. ред. В. В. Дементьева, Ю. Ю. Иерусалимский. - Ярославль, 2008. - С. 12-16.

4. Власова, О. А. Сакральная сфера в деятельности римского претора / О. А. Власова // Проблемы истории, филологии, культуры. - 2012. - № 1. C. 43-49.

5. Дементьева, В. В. Взаимоотношения диктатора и начальника конницы в ранней Римской республике (V-III вв. до н. э.) / В. В. Дементьева, Н. Н. Трухина // Проблемы истории, филологии, культуры. - 1995. - № 2. - С. 107-114.

6. Дементьева, В. В. Магистратская власть римской Республики: содержание понятия imperium / В. В. Дементьева // ВДИ. - 2005. № 4. - C. 46-76.

7. Дементьева, В. В. Римская магистратура военных трибунов с консульской властью / В. В. Дементьева. - М., 2000.-202 с.

8. Дигесты Юстиниана : пер. с лат. / отв. ред. Л. Л. Кофанов. - М. : Статут, 2008. - Т. I (кн. I-IV). $584 \mathrm{c}$.

9. Кофанов, Л. Л. Генезис преторского права в Риме IV в. до н. э. / Л. Л. Кофанов // Forum Romanum. Доклады III Международной конференции «Римское частное и публичное право: многовековой опыт развития европейского права». Ярославль - Москва, 25-30 июня 2003 г. - М., 2003. C. $10-15$.

10. Лукьянец, А. В. Изучение римской должности praefectus urbi в зарубежном антиковедении XIX в. / А. В. Лукьянец // Tabularium. Труды по антиковедению и медиевистике / отв. ред. В. В. Дементьева. - М., 2003. - Т. 1. - С. 76-85.

11. Марк Туллий Цицерон. Диалоги. - М., 1994.

12. Муромцев, С. А. Гражданское право древнего Рима / С. А. Муромцев. - М., 2003.

13. Сморчков, А. М. Религия и власть в Римской республике: магистраты, жрецы, храмы / А. М. Сморчков. - М. : ЗГГУ, 2012. -602 с.

14. Brennan, C. The Praetorship in the Roman Republic / C. Brennan. - Oxford, 2000.-Vol. 1.-880 p.

15. Mommsen, Th. Römische Staatsrecht / Th. Mommsen. - Leipzig, 1874. - Bd. 2. 


\section{ТЕОРИЯ И ПРАКТИКА ГОСУДАРСТВЕННО-ПРАВОВОГО РАЗВИТИЯ}

16. Niebuhr, B. G. Lectures on the History of Rome: From the Earliest Times to the Commencement of the First Punic War / B. G. Niebuhr. - London, 1848.

17. Rucicski, S. Praefectus Urbi. Straznik porzadku publicznego w Rzymie w okresie wczesnego Cesarstwa / S. Rucicski. - Poznan, 2009. - 290 s.

\section{REFERENCES}

1. Borovkov P.S. Kollegiya pontifikov $v$ politiko-pravovoy strukture rimskoy civitas (ot tsarskogo perioda do kontsa Klassicheskoy respubliki): dis. ... kand. ist. nauk [The Collegium of Pontifices in the Political and Legal Structure of the Roman Civitas (from the Period of Kings to the End of the Classical Republic). Cand. hist. sci. diss.]. Ekaterinburg, 2009.231 p.

2. Vlasova O.A. Deyatelnost rimskogo pretora: custodia urbis [The Activities of the Roman Praetor: Custodia Urbis]. Dementyeva V.V., ed. Gorod v Antichnosti i Srednevekovye: obshcheevropeyskiy kontekst: dokl. Mezhdunar. nauch. konf., posvyashch. 100-letiyu g. Yaroslavlya. Ch. II [The City in Antiquity and in the Middle Ages: Common European Context. Reports of the International Academic Conference Devoted to the $100^{\text {th }}$ Anniversary of the City of Yaroslavl. Part 2]. Yaroslavl, 2010, pp. 31-33.

3. Vlasova O.A. Diplomaticheskie obyazannosti pretora v Rime [Diplomatic Duties of the Praetor in Rome]. Dementyeva V.V., Ierusalimskiy Yu.Yu., eds. Yaroslavskiy khronograf: dokl. nauch. konf., posvyashch. 20-letiyu ist. fak. YarGU [Yaroslavl Chronograph: Reports of the Academic Conference Dedicated to the $20^{\text {th }}$ Anniversary of the Faculty of History, Yaroslavl State University]. Yaroslavl, 2008, pp. 12-16.

4. Vlasova O.A. Sakralnaya sfera $v$ deyatelnosti rimskogo pretora [The Sacred Sphere in the Activity of the Roman Praetor]. Problemy istorii, filologii, kultury, 2012, no. 1, pp. 43-49.

5. Dementyeva V.V., Trukhina N.N. Vzaimootnosheniya diktatora i nachalnika konnitsy v ranney Rimskoy respublike (V-III vv. do n. e.) [The Relationship between the Dictator and the Master of the Cavalry in the Early Roman Republic (the $5^{\text {th }}-3^{\text {rd }}$ cc. BC)]. Problemy istorii, filologii, kultury, 1995, no. 2, pp. 107-114.
6. Dementyeva V.V. Magistratskaya vlast rimskoy Respubliki: soderzhanie ponyatiya imperium [Magistracy Authority of the Roman Republic: Definition of the Concept Imperium]. VDI, 2005, no. 4, pp. 46-76.

7. Dementyeva V.V. Rimskaya magistratura voennykh tribunov s konsulskoy vlastyu [Roman Magistracy of Military Tribunes with Consular Authority]. Moscow, 2000. 202 p.

8. Kofanov L.L., ed. Digesty Yustiniana: per. $s$ lat. [Digests of Justinian: Translation from Latin]. Moscow, Statut Publ., 2008, vol. I. 584 p.

9. Kofanov L.L. Genezis pretorskogo prava v Rime IV v. do n. e. [Genesis of the Praetor of Law in Rome in the $\left.4^{\text {th }} \mathrm{c} . \mathrm{BC}\right]$. Forum Romanum. Doklady III Mezhdunarodnoy konferentsii «Rimskoe chastnoe i publichnoe pravo: mnogovekovoy opyt razvitiya evropeyskogo prava» (Yaroslavl, Moskva, 2530 Iyunya 2003) [Forum Romanum. Reports of the $3^{\text {rd }}$ International Conference 'Roman Private and Public Law: Centuries-Old Experience of European Law Development (Yaroslavl, Moscow, 25-30 June 2003)]. Moscow, 2003, pp. 10-15.

10. Lukyanets A.V. Izuchenie rimskoy dolzhnosti praefectus urbi v zarubezhnom antikovedenii XIX v. [The Study of the Roman Profession Praefectus urbi in Foreign Antiquity of the $19^{\text {th }}$ Century]. Dementyeva V.V., ed. Tabularium. Trudy po antikovedeniyu i medievistike. T. 1 [Tabularium. Works on Antique Studies and Medieval Studies]. Moscow, 2003, pp. 76-85.

11. Mark Tulliy Tsitseron. Dialogi [Dialogues]. Moscow, 1994.

12. Muromcev S.A. Grazhdanskoe pravo drevnego Rima [The Civil Law of Ancient Rome]. Moscow, 2003.

13. Smorchkov A.M. Religiya $i$ vlast $v$ Rimskoy respublike: magistraty, zhretsy, khramy [Religion and Power in the Roman Republic: Magistrates, Priests, Temples]. Moscow, 2012. 602 p.

14. Brennan C. The Praetorship in the Roman Republic. Vol. 1. Oxford, 2000. 880 p.

15. Mommsen Th. Römische Staatsrecht. Vol. 2. Leipzig, 1874.

16. Niebuhr B.G. Lectures on the History of Rome: From the Earliest Times to the Commencement of the First Punic War. London, 1848.

17. Rucicski S. Praefectus Urbi. Straznik porzadku publicznego w Rzymie w okresie wczesnego Cesarstwa. Poznan, 2009. 290 p. 


\section{Information about the Author}

Olga A. Vlasova, Candidate of Sciences (History), Associate Professor, Department of History and Theory of State and Law, Yaroslavl Branch of Moscow Finance and Law Academy, Kuznetsova St., 1, 150054 Yaroslavl, Russian Federation, ol.vlasova123@gmail.com.

\section{Информация об авторе}

Ольга Александровна Власова, кандидат исторических наук, доцент кафедры истории и теории государства и права, Ярославский филиал Московской финансово-юридической академии, ул. Кузнецова, 1, 150054 г. Ярославль, Российская Федерация, ol.vlasova123@gmail.com. 